tutions whose infinitely valuable opportunities are, under the present order of things, entirely wasted would be of incalculable value." And with this opinion Dr. Allbutt, after all, does not appear to disagree, for, a little further on in his address, we tind him actually advocating such a measure.

"Nevertheless, I agree with Mr. Wheelhouse that an apprenticeship to the domestic side of your work, a familiarity with its lesser marks and byeways, is necessary. These we cannot teach here. After your faculties are trained and strengthened in their main branches, your lesser shoots shall be duly laid in. But with capacities thus enlarged, one year's apprenticeship would do the work of five in earlier age; and an obligation upon young men thus to apprentice themselves before the completion of their studies would have my approbation and active support."

Wherein, then, lies the great difference between us? Simply as to the time (the old, old question) at which pupilage may be most advantageously taken. I think that rudimentary knowledge should be sought in the earlier years of studentship. Dr. Allbutt, in common with many others, would place it later on; and when a man's mind has been expanded by converse with his fellows and by the scientific observation of the phenomena of disease, and is truly and rightly aflame after higher knowledge, higher reasoning, and higher aspirations, he would put him back to the bare study of the Pharniacopoeia, and to the acquirement of those rudiments of medical education which can only then be a weariness to his soul and a degradation to his energies. The difference between us, infinitely great as it is, is not one of "principle" after all, but only a question as to the choice of time, and is hardly such as to call for the old story of the Chinaman, who was so devoted to roast pig that he was ready at any time to burn his house down that he might revel in his favourite dish.

I am, Sirs, your obedient servant,

Leeds, October, 1889.

C. G. WheElhouse.

\section{WHY DOES THE UTERUS CONTRACT DURING PREGNANCY?}

\section{To the Editors of THE LANCET.}

SiRs,--Under the above heading, in your last issue, Mr. Wade of Chudleigh, in a letter throwing out a suggestion as to the cause of these contractions-namely, the presence of blood overcharged with carbonic acid, says: "We have the authority of Playfair for the statement that the intermittent contractions of the uterus occur every five or ten minutes, sometimes oftener, rarely at longer intervals, throughout the whole of gestation." I hope it may not be considered a piece of unpardonable egotism if I take this opportunity of pointing out that the subject was first introduced by me in a paper read so long ago as Oct. 4 th, 1871 , before the Obstetric Society of London, and subsequently added to in papers on the same subject at three International Medical Congresses, and published in their proceedings. The first paper will be found in the Obstetrical 'Transactions, London, vol. xii. In it, page 219, I remarked: "It may be that the semi-stagnant state of the blood (that is, of course, charged with carbonic acid) in the uterine sinus \&c. may provoke contractions, but certainly there is some other excitor than either foetal movements or the irritation of the various nerves in sympathetic connexion with the uterus." Of course this suggestion is the same in essence as Mr. Wade's; but we both derive our inspiration with the idea thrown out, I think, by Brown. Séquard-namely, that the presence of carbonic acid in excess in the uterine sinuses causes the uterus to contract. I cannot find that he gives " much evidence in proof, but it is a fair working theory ; and I also think it may be assumed as one of the factors in the genesis of labour." But there are other acrents concerned in the movements of the blood in the walls of the uterus and placenta; and to these I have salled attention in a note published in the Proceedings of the Royal Society, 1879: "Note on the Auxiliary Forces concerned in the Circulation of the Pregnant Uterus and its Contents in Woman." These transcendental points seldom get into text-books where Mr. Wade has been looking, or if they do, it is many years after their introduction; and even some text-books of modern date have altogether omitted noticing these contractions and the great help they give in the diagnosis of pregnancy. Mr. Wade, however, remarks : "We are all familiar with the facts that the chorionic villidip freely into the sinuses of the uterine wall, and that in this situation an exchange takes place between the fluids on the foetal and maternal sides of the villous membrane which alone separates them." I am quite willing to concede an exchange, but not through one membrane alone; and I cannot include myself in the "all," as may be seen in my "Anatomy of the Human Placenta" (Obstet. Trans. Lond.). However this may be, if Brown-Séquard's theory be correct, the retention of semi-stagnant blood, highly and increasingly charged with carbonic acid and effete foetal matter, is probably the immediate stimulas required to produce the uterine contractions I have pointed out, and which acts as a supplementary heart. The contractions act, it should be observed, independently of any external irritation. Up to the present time I have had no co-worker in this subject; when other observers take it up, probably newer points will be brought to light.

I am, Sirs, yours obediently,

George-street, Hanover-square, Oct. 3rd, 1889 J. BRAXTON HICKs.

\section{REMARKABLE SURVIVAL AFTER MULTIPLE PISTOL-SHOT WOUNDS.}

\section{To the Editors of THE LANCET.}

SIRs,- The following case may interest those of your readers who perused the articles in THE LANCET of Sept. 14th, 21st, and 28th, under the heading, "Five Cases Illustrative of Cerebral Surgery."

On the evening of Oct. 13th, 1881, W. L_- aged twentyone, a rural postman, was seized by a would-be assassin, who fired several shots at him from a revolver, and having expended his own ammunition, called to a companion to "have at him now"; this man then continued the attack, and fired into their victim. One of the bullets entered the brain, where it still remains, and causes little if any inconvenience, although for nearly two years he could not bend his head or lean forward without giving rise to great pain and unpleasant symptoms. On making my examination I found a bullet wound on the left side of the head, about half an inch posterior to his ear, and immediately beneath the parietal eminence. Through this wound the brain substance exuded, and a small probe passed directly inwards for a distance of about two inches by merely letting it drop into the wound. On examining with tip of little tinger, no spicula could be found. Another bullet entered the left temple just above the zygomatic arch, about an inch and a quarter from the edge of the orbit; it took an inward and downward direction ; its course, however, could not be traced. Another hit the angle of the jaw, took an upward direction, and was held between two molar teeth. One entered the left side of the chest on a line with the nipple, an inch and a half posterior to it, passed through the chest, and was extracted from the right axilla. One glanced off the great trochanter, and became lodged in the lumbar muscles. Two passed through the forearm about the middle. One entered the forearm about two inches from the wrist, took an upward course, and was extracted near the elbow-joint. One passed through the hand between the thumb and index finger. The skin on the left forearm and wrist was destroyed, the clothing having been set on fire by the powder. On the right hand the metacarpophalangeal joint was destroyed by the charge from a pistol loaded with shot, several grains of which and some of the paper used for "wad" were extracted from the palm of hand. The man was almost pulseless, and, the case seeming hopeless, it was decided by Dr. Allen and myself not to interfere except symptoms demanded it further than to cleanse and dress the wounds, carbolic lotion being used. He was given brandy and new milk or beef-tea every half hour. Coughing was severe for some days, and there was considerable hæemorrhage from the lungs. He had also a sharp attack of double pneumonia. He was kept perfectly quiet and cool, morphia being given in minute doses hypodermically to relieve the cough, which caused terrible pain in his head. On the fifth day after being wounded he had considerable delirium, and could hardly be restrained, as he was " afraid of being taken to an asylum " at one time, while at another he thought his assailants were amain attacking him.

This case, besides being interesting, I consider very important from the fact that, although being so fearfully wounded, the man did not lose consciousness till some time after he was brought to the police barracks, where he described one of his assailants and fully identified him. He was also able to describe a man who passed him soon after the attack; he also dragged himself to a house a few: 
yards from the outrage, begged to be admitted, and when refused, and feeling faint, hid the mail bags, and after "coming to" crawled to another house, prayed for admission, and to send for a priest. Being again refused, he "dropped down to die." He has no idea how long he lay there, but hearing a car pass he made an effort, and got to the road, where he was found in a fainting state by the police sent to look for him. The bullets removed were $\cdot 450$, or about the same size as those used for the British bulldog revolver. I am, Sirs, yours faithfully,

County Infirmary, Longford, oct. 3rd, 1889.

N. MAYNE.

\section{EXFOLIATION OF ALVEOLAR PROCESSES.} To the Editors of THE LANCET.

SIRs,-I see Mr. R. Clement Lucas, in giving notes of two cases of necrosis of the alveolar processes following measles, which appeared in your last impression, says that he does not know of any case of typhoid fever resulting in exfoliation of the alveolar processes of the jaws. As such a case occurred in my practice a year ago, it is perhaps of sufficient interest to place on record.

W. H- a lad of sixteen, sent for me on Aug. 30th, 1888. I found a well-marked case of typhoid fever, and the patient for a fortnight, or the latter half of September, was in a semi-conscious condition, requiring rousing for a part of that time to take nourishment \&c. On Oct. 10th the left half of the lower maxilla was noticed to be swollen, and afterwards there was fetid breath with foul-smelling mouth and gumis. On the 17th he had pulled out the two lower left incisors, and the canine molars were found to be loose, whilst the alveolar process was also loose and evidently necrosed. He was sent to the London Hospital, his friends not being able to stand the drain on their resources, and the alveolar process, including the sockets of all the teeth of the left half of the lower maxilla, eventually was taken away, leaving the lad one side of his face fresh and juvenile and the other side very grandmotherly looking indeed.

I am, Sirs, yours truly,

MILLICE CULPIN, L.R.C.P., L.R.C.S.Edin.

Stamford-hill, Oct. 5th, 1889.

\section{NAPHTHALIN.}

To the Editors of THE LANCET.

SIRS,-May I ask for space to add my testimony to the value of naphthalin in the class of case Dr. Angel Money refers to in his letter published in your last issue? In conjunction with the diet advocated by him, I have found nothing so serviceable as the drug in question. It is equally serviceable in the epidemic infantile diarrhœa for which Nottingham occupies an unenviable position, together with Leicester and Oldham.

I am, Sirs, your obedient servant,

Nottingham, Oct. 7th, 1889. LEWIS W. MARSHaLL.

\section{MANCHESTER.}

(From OUR OWN CoRREspondent.)

\section{The Session 1889-90}

ON all sides the work of the coming session has begun. The Owens College had its opening day on the lst inst., when Professor Schuster delivered the inaugural address, taking for his subject, "University Teaching in its relation to the Industrial Application of Science." This makes the fortieth session of the College, and the few who can look back and remember the first of these must be struck by the rapid and wonderful strides the College has made in arriving at its present position. On the same day the half-yearly meeting of the court of governors was held, an interesting feature of which was the presentation to the College by a number of subscribers of a portrait of Mr. Alfred Neild, who for a considerable length of time has been its treasurer. The financial report for the past year was satisfactory, the expenditure having kept within the income. On the evening of the same day the medical department of the College had its own special opening in the shape of a soirée, at which nearly a thousand visitors were present. The guests were received by the dean of the medical school (Dr. Young), and several nembers of the court of governors \&c. Subsequently the dean presented the report for the past year, which shows a highly satisfactory condition of the school from every point of view. Various exhibits, demonstrations, drawings \&c. were provided for the amusement and instruction of the visitors, and Professor Dreschfeld gave a very interesting résumé of our present knowledge concerning leprosy. On Wednesday, the following evening, the first meeting of the Medical Society was held, and, following a practice which appears to be becoming common, of inviting gentlemen from a distance to give papers at the opening meeting of our societies, Dr. Hughlings Jackson was asked to visit Manchester, and delivered an address upon "Respiratory, Toxic, and Traumatic Convulsions." On Friday evening next the annual medical dinner will take place at the Queen's Hotel, under the presidency of Dr. Little, and after then we may hope to settle down steadily to work all round.

\section{The Proposed New Hospital.}

It is with great regret that I have to record the fact that the munificent offer of the Whitworth trustees to Owens College of a sum of some $£ 70,000$ has been lost. The trustees undertook to provide money to erect a hospital with sixty beds, and endow it with $£ 2000$ per annum, to become the property of the College, but they wished it to be more or less connected with the Royal Infirmary, the latter body to take an active share in its management. After nearly twelve months of negotiations between the two bodies the Infirmary Board at its last meeting declared themselves unable to accept the conditions proposed, and the trustees have now withdrawn their offer. It is an open secret that the relations between the College and the Infirmary have for some time been considerably strained. The College authorities, as representing the medical school, desire to have some control over or voice in the arrangements for the clinical instruation provided for their students, but this the Infirmary has not been willing to accede to; other matters also have caused no inconsiderable friction between the two bodies, but it is to be hoped that in the interests of the Infirmary, the College, and the public at large, some modus vivend $i$ may ere long be arrived at, and that this handsome proffered gift may not be irretrievably lost.

Salford and its Fever Hospital.

$O$ wing to the great prevalence at the present time of scarlet fever and diphtheria in the neighbouring borough, great difficulty has arisen in providing hospital accom. modation for all the cases which it is desirable to isolate; and it was stated last week that the wards of the Wilton Hospital are crowded far beyond their proper accommodation. If this be so, it is no light matter; for of all patients those suffering from infectious disease are the last that should be stinted in the proper cubic space and air-supply within their wards. In Manchester itself the cases of scarlet fever are also so numerous that the Infirmary Fever Hospital cannot take the surplus Salford patients; and hence the health authorities of the latter are seeking the help of the guardians to provide them with hospital accommodation at Hope. In the meantime the proposed new fever hospital for the Salford Corporation is still in the clouds.

Prevalence of Scarlet Fever.

During the present epidemic of scarlet fever, and now that the notification of infectious disease can, by means of the recent new Act, be easily put in operation, it is to be hoped that all the surrounding smaller districts will at once put it in force, and the whole of the population comprised in "Greater Manchester" thus be placed under the same conditions, so far as obtaining knowledge of the. existence of these diseases is concerned.

\section{Unhealthy Dwellings.}

At last the Corporation has made a distinct move in grappling with this subject. At the last meeting of the City Council a "presentment" was made by the medical officer, condemning what has long been known as one of the most insanitary areas in the Ancoats district. It was this area to which Dr. Thresh a short time ago drew particular attention in a special report that he made thereon to the sanitary association. It is pleasing to note that Dr. Thresh's work has not gone unnoticed, and he has just been appointed officer of health to Chelmsford.

Manchester, Oct. 8 th 